\title{
"Wonderful Indonesia" country marketing campaign - how visible Indonesia as a tourism destination for Europeans
}

\author{
Slavomír Rudenko \\ Pan-European University, Bratislava, Slovakia \\ Adi Prasetyo Tedjakusuma \\ University of Surabaya, Surabaya, Indonesia
}

\begin{abstract}
Even though the campaign has been intensively presented in Indonesia and throughout the world as the main marketing campaign for Indonesian tourism, it remains questionable in how successful the campaign is in attracting more potential international tourists to visit Indonesia. Out of a general examination of the country marketing campaign, its contents and position in the contemporary international marketing approach, the aim of this study was to concentrate on the visibility and the outreach of the marketing campaign in Europe, most notably in Slovakia as a rather Europe's less populous nation. The paper examined the approaches, the challenges and the results of the campaign in a geographically far away region with historically very limited prior bilateral affiliation. Thus, the majority of activities towards a better visibility of Indonesia are initiated and/or conducted almost purely by its official diplomatic representation in the host country.
\end{abstract}

Keywords: country marketing, tourism destination, soft diplomacy, interculturality

\section{INTRODUCTION}

In the broadest possible sense, tourism takes place when a person leaves the local environment (place of residence) to visit other places (in the same country or a country different from the country of origin) to engage in any activities there. These may be numerous, ranging from visiting friends, activities of economic or professional interest, to pure free time and leisure activities. In order to reach out and influence the decision to visit a specific country, marketers of the respective destination need to implement country marketing in order to promote their place and the activities to indulge in there (Fyall \& Garrod 2005)

Country (or nation) marketing has evolved to become a very important, if not the most essential, tool to reach out to the general public, national and international, to highlight the country and its opportunities as such (Tsay 2012). It is clearly not the primary intention of this paper to make a comparative analysis of the history and the country marketing strategies of different countries; it has become clear that certain countries demonstrate a long history of effi cient country marketing mechanisms. To mark an example region-ally relevant for this study, an official marketing strategy of Singapore to present the attractiveness of the city-state as a shopping and entertainment hub of South-East Asia has been launched already in 1985.

Recognizing the importance of country marketing to attract foreign tourists, Indonesia developed "Wonderful Indonesia" campaign back in 2011. Indonesia's first real effort to boost tourism marketing may be seen in the 1990s when the "Visit Indonesia Year" was launched. It was, however, not before 2011, when the Indonesian Ministry of Tourism followed the examples of country branding campaigns like Malaysia, Thailand, and India, launching a modern, fresh marketing campaign, called "Wonderful Indonesia" (https://travel.detik.com/travelnews/d-2765967/wonderful-indonesia-bakal-jadibranding-pariwisata). Not only the country as an attractive travel destination was presented but also, and more notably, the 4th most populous country of the world, with a notable economic potential, has opened up to market itself internationally in a trend of creative and up-to-date country marketing. Even 
though the figures, showing the growth of international visitors to Indonesia, as a direct consequence of this campaign, may seem remarkable, the results need to be examined a little bit more cautiously.

From 2010 onwards, the annual increase of new visitors has reached roughly between 7 and 10 percent, a tendency of growth, which official Indonesian authorities use to slightly overestimate. In a more relevant regional comparison, it becomes clear that Indonesia, with its varied offer of tourism destinations, ranging from rich cultural variety, through a massive selection of attractive beachside and diving locations, wild-nature, hiking and other outdoor opportunities still stays far behind the tiny island city-state of Singapore, a much smaller Malaysia or over the years well-recognized tourism country as Thailand and even Vietnam, slowly reaching the numbers of Indonesia from behind. The 2015 data showed that Indonesia received 11 million foreign tourists which was still behind Thailand with 30 million foreign visitors, Malaysia with 26 million visitors and Singapore with 16 million tourists (https://hotelandtourismonline.com/2016/12/02/conn ecting-more-indonesian-places-for-tourism). It can be, thus, seen, that advertising a country requires much more than allocating ambitious amounts of budgets for country promotion.

\section{RESEARCH METHODS}

The paper examined the approaches, the challenges and the results of the Wonderful Indonesia campaign in Central and Eastern Europe (CEEC) countries that are geographically far away with historically very limited prior bilateral affiliation.

The study applied descriptive research method using primary data of interview with subjects from CEEC countries and observation as well as secondary data from articles, newspaper, data center, books, and website.

\section{RESULTS AND DISCUSSION}

\subsection{Challenges for a country - Indonesia as a showcase}

As a success story for country marketing, Malaysia can be drawn as an example. Although much smaller than Indonesia in size, Malaysia has succeeded to highlight the potential and its features of uniqueness to the outside world. It has also proven a direct link between an effective nation branding and a nation's tourism development. There are examples to be found which show that a visible nation marketing campaign does not necessarily lead to a growth of international visitors, even though the general visibility of the country as such may be raised.

The country marketing strategy "Wonderful Indonesia "aims clearly to mark the uniqueness of the country's nature, people, culture, traditions and modernity and in more general, the effect, which the country might create towards a visitor, or a pure audience of the campaign, defining the country as "wonderful" (Gali et al. 2016), Analyses have claimed that not all target audience may interpret the message in the same way. The value of Indonesia's natural beauty may be admitted, but expecting more, since every country has its own natural beauty. Thus, a unique selling proposition is missing, like for example the promotion of the unique multiculturalism of Indonesia or the ethnic, cultural and religious pluralism, most countries do not have, but which Indonesia represents and has a great potential to be promoted (Poyk \& Pandjaitan 2016).

\subsection{Country marketing as a tool of "soft diplomacy"}

It would be just a very simplified approach to consider the country marketing's success purely under the indicator of whether and in what amount the growth of tourist numbers have taken place as a consequence of a country marketing strategy. Examples may be shown that certain countries awake more interest than others do in different parts of the world. Well-presented country marketing may thus serve as a good tool to raise awareness about a country or switch already existing perceptions in the general public (Tsai 2012).

The Global Country Brand Index is a study of countries' comparative perception, compiled by a consultancy group, FutureBrand, which aims at measuring the perception of the value of countries as brands in the business corporate sector (www.futurebrand.com/country-brand-index). As already referred to above, Indonesia, as the 4th most populous country of the world and the world's 16th 
most powerful economy ranks as number 66 in the country brand rankings, which makes it ranked only as "country", not reaching the level of "country brand" (The 4 levels to be reached are "country brands" - "status countries" - "experience countries" - "countries"). The reputation for high quality products, the desire to visit or to study in a country and the quality of infrastructure in a country are considered to be the leading preceptors while looking at a country under the mentioned study.

The cause for a country not to be well-known around the world may be manifold. Shortages of strong global brands, low visibility of personalities who may serve as global ambassadors of a country, lack of an active diaspora abroad can be listed as examples. As a matter of consequence, a limited knowledge about a country can dramatically influence the international economic capability of the country, hinder its diplomacy, and last but not least, as it is the main scope of this study, prevent potential tourists from choosing a country as their desired travel destination (Avraham 2009).

A well-structured and well-communicated country branding campaign can, thus, not only bring more visitors to a country, but, more notably, raise positive emotions about a place which might have been overseen or not enough in attention.

Since its first launched in January 2011, the "Wonderful Indonesia" country marketing campaign has been presented and promoted in various ways. Whether just as a slogan or in numerous forms of audio-visual outcomes it has, quite logically, concentrated in being presented at places of a high international outreach. A total number of 22 airplanes of the Indonesian national carrier Garuda Indonesia have continuously presented the "Wonderful Indonesia" promotion and marketing campaign on its all inbound and outbound international flights. The official "Wonderful Indonesia" country marketing video was broadcasted through a range of world's leading media channels and posters were placed at frequented places and vehicles of public transport in world's famous cities, such as Paris, London, Amsterdam, Beijing, Shanghai, Hong Kong, Tokyo, Singapore, Seoul, Bangkok and Melbourne. Most notably, the main achievement of the campaign was the recently awarded "Best travel and tourism video for East Asia and the Pacific Region" and the "People's Choice" awards by the United Nations World Tourism Organization for the "Journey to a Wonderful Indonesia" country marketing video trailer (http://www.indonesia.travel/en/post/breaking-newsthe-journey-to-a-wonderful-indonesia-video-winsnot-one-but-two-awards-in-unwto-tourism-videocompetition). All the mentioned facts might, thus, demonstrate that the Indonesian official country marketing has reached a good international visibility and as a result, received a positive feedback (D’Angella \& Go 2009).

Nevertheless, cities and countries which are less populous and which might have a lower global outreach have not been significantly covered so far. Examples from the countries of Central and Eastern Europe may be shown, where a larger public is showing interest in visiting the region of South-East Asia, but among whom due to a better visibility and frequent promotions from the travel industry Thailand as a desired destination dominates clearly in the relevant sub-region (Gali et al. 2016). Therefore, since a direct promotion of the country is not being addressed directly by the Indonesian state authorities (like the Ministry of Tourism), as in case of the examples presented above, it is up to the diplomatic missions of Indonesia to execute the promotion of Indonesia in the respective host countries, using various tools of "soft diplomacy", including presentations, cultural events, participation to fairs and exhibitions, etc.

\subsection{Challenges for cultural diplomacy as part of country promotion and marketing}

Out of an Indonesian perspective, the countries of CEEC represent a geographically far away region, with a considerably limited direct historical, cultural or religious affiliation. Also, political and commercial contacts were and also presently continue to remain rather modest. Thus, the diplomatic representations face the difficulty in how to address the host country with the right feel of sensitivity and directness.

It has become a well-established practice of the diplomatic representations of Indonesia in CEEC to organize various country events, participation to exhibitions and fairs, presentations, music and dance performances, following the objective to bring Indonesia closer to the population of the host countries. They generally aim at creating a first, introductory emotion about Indonesia, thus introducing Indonesia as a travel destination for a different travel experience. A country with a very rich cultural life and heritage, through a European perspective seen as exotic and characterized by colorfulness, which is omnipresent in regard to the way of life, the varied cultural life in the distinct regions of Indonesia and demonstrable by works of arts, costumes, musical instruments as well as traditions or habits representative for the respective regions. The best ways to connect the appealing visual perception with the pure delight of Indonesia are the tastes and flavors of Indonesian culinary products, which are very little known in CEEC. Cultural presentations combining 
Indonesian music or dance with a taste of Indonesia at specialized events of specialty coffee, teas, cocoa, chocolate, sugar, etc., accompanied by tasting of delicacies of Indonesian cuisine are the most likely to successfully create a lively experience, which Indonesia may offer even in a faraway country as a kind of a spin-off effect for official country marketing.

Due to the specificities and knowledge of local products and the ability to present them as a different cultural experience in an authentic way a diplomatic representation of Indonesia is very likely to show its country in a very authentic style. The embassy activity can strategically be supported by the marketing and product/service oriented promotion of products, originating in Indonesia, by local entrepreneurs, such as travel agents, importers, and distributors of Indonesian products. Complemented by an already existing official country marketing campaign cultural and commercial events seem to bring more result to make a country visible abroad by addressing a considerably wide public in a very natural and unpolitical way, rather than what might become the outcome of an often too stringent, dressy and stiff traditional diplomacy reaching only few spin-off effects towards the local populations. Quoting the words of the former Ambassador of Indonesia to Slovakia (2012-2017), H.E. Djumantoro Purbo, "Intercultural interaction, encompassed in people-topeople contacts remains the best recipe for success in showcasing a country, so manifold and diverse as Indonesia. The Wonderful Indonesia country marketing campaign has helped to reach a better understanding to associate the visual beauty of the Indonesian archipelago with the richness of tastes and flavors of Indonesia presented through Indonesian

culinary events. As a matter of consequence, the decision to visit Indonesia becomes the best testimonial of what an audio-visual country marketing address wants to convey."

\section{CONCLUSIONS}

The general question of how the idea and an intention to raise the visibility of Indonesia can best be served, cannot be answered in a simplified way (Pike 2005). Thus, it has been demonstrated in this paper that a purely political or business style tourism marketing of a country in a faraway region of the world with limited prior bilateral links might not be the most suitable solution. Thus, it may be advised, and as the general practice shows, country events, presenting the richness of culture, arts, the natural features of various geographic locations, their culinary products and local specialties might seem as a discreet, though efficient way of country marketing and serve as a tool of "soft" intercultural diplomacy, with emotions creating effects towards the targeted country or region and the respective general public.

\section{REFERENCES}

Avraham, E. 2009. Marketing and managing nation branding during prolonged crisis: The case of Israel, Place Branding and Public Diplomacy 5: 202-212

D’Angella F. \& Go, M.F. 2009. Tale of two Cities' Collaborative Tourism Marketing: Towards a Theory of destination stakeholder assessment, Tourism Management 30: 429-440

Fyall, A. \& Garrod, B. 2005. Tourism Marketing: A Collaborative Approach, Channel View Publications

Gali N., Camprubí R. \& Donaire, A. J. 2016. Analyzing tourism slogans in top tourism destinations, Journal of Destination Marketing \& Management

Pike S. 2005. Tourism Destination Branding Complexity, Journal of Product \& Brand Management 14/4: 258-289

Poyk, M.D.S. \& Pandjaitan, A.Y. 2016. Representation of Indonesia in Wonderful Indonesia's Feeling is Believing Tourism Advertisement. A Critical Discourse Analysis, $\mathrm{Pa}$ radigma Journal Kajian Budaya. 6(1): 102-122

Tsai, S. 2012. Place Attachment and Tourism Marketing: Investigating International Tourists in Singapore, International Journal of Tourism Research 14: 139-152

https:/travel.detik.com/travel-news/d-2765967/wonderfulindonesia-bakal-jadi-branding-pariwisata (Accessed on October 10th, 2017)

http://ravel.kompas.com/read/2016/10/27/170900927/.wonderf ul.indonesia.menangi.best.destination.marketing.award.201

6 (Accessed on October 14th, 2017)

$\mathrm{http} / /$ www.indonesia.travel/en/post/breaking-news-thejourney-to-a-wonderful-indonesia-video-wins-not-one-buttwo-awards-in-unwto-tourism-video-competition (Accessed on October 10th, 2017)

www.futurebrand.com/country-brand-index (Accessed on October 17 th, 2017)

https://hotelandtourismonline.com/2016/12/02/connectingmore-indonesian-places-for-tourism/ (Accessed on October 17th, 2017) 